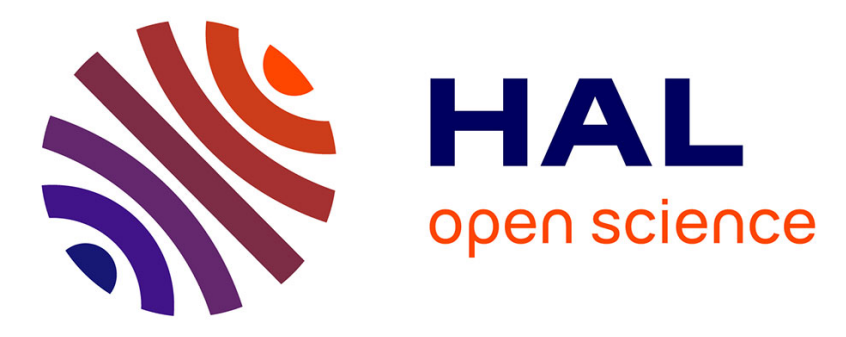

\title{
Solenoidal Transformers for Magnetic Materials Integration
}

Lamine Ourak, Ayad Ghannam, David Bourrier, Christophe Viallon, Thierry Parra

\section{- To cite this version: \\ Lamine Ourak, Ayad Ghannam, David Bourrier, Christophe Viallon, Thierry Parra. Solenoidal Trans- formers for Magnetic Materials Integration. 2012 Asia-Pacific Microwave Conference, Dec 2012, Kaoh- siung, Taiwan. p1 - 4, 10.1109/APMC.2012.6421757 . hal-00783047}

\section{HAL Id: hal-00783047 https://hal.science/hal-00783047}

Submitted on 1 Feb 2013

HAL is a multi-disciplinary open access archive for the deposit and dissemination of scientific research documents, whether they are published or not. The documents may come from teaching and research institutions in France or abroad, or from public or private research centers.
L'archive ouverte pluridisciplinaire HAL, est destinée au dépôt et à la diffusion de documents scientifiques de niveau recherche, publiés ou non, émanant des établissements d'enseignement et de recherche français ou étrangers, des laboratoires publics ou privés. 


\title{
Solenoidal Transformers for Magnetic Materials Integration
}

\author{
Lamine Ourak $^{\# *}$, Ayad Ghannam ${ }^{\#}$, David Bourrier ${ }^{\#}$, Christophe Viallon ${ }^{\# *}$, Thierry Parra ${ }^{\# *}$ \\ ${ }^{\#}$ CNRS ; LAAS ; 7 avenue Colonel Roche, F-31400 Toulouse, France \\ *University of Toulouse ; UPS ; LAAS ; F-31400 Toulouse, France
}

\begin{abstract}
This paper presents the design, fabrication and characterization of suspended solenoidal transformers fabricated using a low cost single step 3D copper electroplating process. The design and optimization of solenoidal transformers with and without magnetic core are performed using HFSS. After optimization, the suspended structures reveal good electrical performance. The addition of a magnetic core to these structures shows a significant improvement of its electrical properties. Thus, an increase of $10 \%$ on $G_{\max }, 20 \%$ on coupling coefficient $k, 80 \%$ on the quality factor $Q$ and $350 \%$ on the inductance is observed. Under probe measurements carried on the suspended structures without magnetic core exhibit a Gmax of $-1.45 \mathrm{~dB}$ and a $Q$ of 28.5 at $2.5 \mathrm{GHz}$. The enhanced performance coupled with the low cost $3 \mathrm{D}$ process makes these transformers excellent candidates for today's RF applications.
\end{abstract}

Index Terms - Above-IC, magnetic core, solenoids, threedimensional integrated circuits, transformers.

\section{INTRODUCTION}

Today, RF and microwave applications demands for increased functionality, higher density integration, better passive device performance, reduced footprint and cost are stressing for new enhanced and low cost integration technologies.

Passive components such as transformers are in constant development to enhance their performance and reduce their surface occupation [1]-[2]. Miniaturization, good quality factor $Q$ and high maximum available gain $G_{\max }$ are the main parameters of transformers that enable their integration in high performance RF circuits. Several approaches have been yet introduced like stacking or narrowing the transformer's inductors, 3D integration in silicon [3] and/or inserting a magnetic material. These approaches suffer mainly from high process complexity/cost and from incompatibility with an above-IC processing.

In this work, we present the development of high performance suspended solenoidal transformers operating at $0.5-15 \mathrm{GHz}$ frequency band and their innovative low cost 3D manufacturing technology [4]. With their reduced footprint, they offer excellent electrical performance since they explore the $3 \mathrm{D}$ process to reduce substrate losses [3]-[5]. In addition to their intrinsic performance, these structures offer the possibility of integrating magnetic cores in order to further enhance their performance. The implementation of magnetic materials increases magnetic couplings then increasing inductor values and the $Q$ factor. In another hand, keeping constant the inductance values, this implementation allows both the reduction of the occupied area by the component and the $Q$ increase.

\section{3D TRANSFORMERS}

\section{A. Design and simulation:}

The solenoidal transformers presented in this paper consist of two nested inductors with suspended parts forming a hollow transformer (Fig. 1a). A magnetic core made of dielectric coated FeCo nanoparticles is easily inserted (Fig. 1b).

Transformers are designed and optimized using electromagnetic simulation software HFSS. The simulations are used to tweak the geometry of the structure in order to optimize its performance and take full advantage of the magnetic core while taking into consideration the constrains imposed by the technology.

Fig. 1. 3D HFSS model of the solenoidal transformers: without magnetic core (a), with magnetic core (b).

During the optimization process, we look at the figure of merit $G_{\max }$ which is the maximum available when input and output impedances are matched [6]-[7]. $G_{\max }$ is calculated using:

$$
G_{\max }=\left|\frac{S_{21}}{S_{12}}\right|\left(k_{s}-\sqrt{k_{s}^{2}-1}\right)
$$

Where, 